\title{
STRESS BEHAVIOR OF TAILOR-WELDED BLANKS FOR DISSIMILAR METALS USING FINITE ELEMENT METHOD
}

\author{
L.C. Wor and M.M. Rahman \\ Faculty of Mechanical Engineering \\ Unviersiti Malaysia Pahang \\ 26600 Pekan, Pahang, Malaysia \\ Email: mustafizur@ump.edu.my \\ Phone: $=6094246239$; Fax: +6094246222
}

\begin{abstract}
This paper presents the stress behavior of tailor-welded blanks (TWBs) for dissimilar metals and identifies the critical locations using the finite element method. By using dissimilar metals with different welding configurations, the critical points where the force is concentrated and the maximum forces that are exerted at those particular points can be estimated. To overcome these issues, simulation using the finite element method is used to estimate the critical point of the TWBs. Steel and aluminum are considered as welding materials. The welding parameters of current, voltage and welding velocity are modified to analyze the effect on the welding part. The different TWB configurations are the L-shape, the T-shape and the plate. Goldak's double ellipsoid source model is used as the heat source in the investigation. The distortion of the plate increases when the power of the laser increases. The distortion is due to the residual stress caused by heating when welding. The residual stress relieved during cooling makes the plate distort. It can be seen that the increase in power increases the temperature since power is the energy source conducting heat to the plate. Thus, the temperature is proportional to the power used. The heat-affected zone increases during the welding process when the power increases. Increasing the power also increases the TWB distortion.
\end{abstract}

Keywords: Finite element method; stress; steel; aluminum; power.

\section{INTRODUCTION}

Nowadays, tailor-welded blanks (TWBs) are very popular in industry, especially in automotive applications, due to competition among the industries. These industries compete in terms of technological innovation to gain the trust and confidence of the customers. Although automotive products have their own features, customers demand more in terms of fuel efficiency, performance, safety, and comfort at the lowest price. [1-5] A TWB consists of two or more sheets that have been welded together in a single plane prior to forming. The sheets have different thicknesses and mechanical properties, which can be joined by various welding processes [6-10]. The weight of the part could be reduced while the strength of the part is maintained. Anand, Chen [11] mentioned that the tailor-welded concept allows the engineer to join the best materials where necessary at the best place according to the material properties within the part. TWBs are popular among automotive applications because the weight of the part in a vehicle is crucial to fuel efficiency and the TWB is a solution in reducing the weight of the part [12]. Higher strength material is used in the critical regions, while lower strength 
material is used in the less critical regions. This could highly reduce the weight of the part and this concept is very useful in automotive applications.

Luo [13] showed that no other material has shown the versatility of steel in automotive applications. Various new grades of steel - interstitial-free (IF), dual phase (DP) and high strength low alloy (HSLA) -which show excellent formability and the ability to meet most automotive requirements have been developed. These grades of steel have penetrated the TWB market alongside raising challenges which include the prediction and evaluation of the performance of these TWBs in forming and their other structural properties. Therefore, determination of the deformation pattern and weld line displacement due to the effects of TWBs in the parts should be investigated. Many methods could be used to analyze the results, among them the numerical method. Finite element modeling and analysis is a well-known predictor of the deformation pattern and weld line displacement when the forces and material properties are accurate. Raymond, Wild [14] carried out an analysis using the finite element method to investigate weldmodeling techniques based on simulation results. The objectives of this study are to determine the stress on TWBs and identify the critical location of the welded blanks and to investigate the effect of power on the welding characteristics of TWBs

\section{METHODS AND MATERIALS}

Welding power is a crucial factor that affects the weld behavior of metal. It is produced by current $(A)$ and voltage $(V)$. To study the behavior, current and voltage are changed independently to test the effect of these parameters. Table 1 shows the current and voltage parameters used in this study. Simulation is carried out five times with different currents and voltages.

Table 1. Parameters used for analysis.

\begin{tabular}{ccc}
\hline Specimen & Voltage $(V)$ & Current $(A)$ \\
\hline 1 & 18 & 300 \\
2 & 18 & 400 \\
3 & 18 & 200 \\
4 & 15 & 300 \\
5 & 25 & 300 \\
\hline
\end{tabular}

Using different materials for welding also affects the weld behavior since each of the materials has its own mechanical properties. Popular materials usually used for TWBs are stainless steel (SS) and aluminum (Al), where SS has considerable fatigue strength and $\mathrm{Al}$ is very light weight. The mechanical properties of SS and Al are shown in Table 2. It can be seen that the ultimate tensile strength of SS is higher than that of $\mathrm{Al}$; however, the density of $\mathrm{Al}$ is much lower than that of SS. This shows that SS can endure higher stress than $\mathrm{Al}$ but $\mathrm{Al}$ is much lighter. The results will be compared to the welding results of SS and SS plate. 
Table 2. Mechanical properties of stainless steel and aluminum.

\begin{tabular}{lcccc}
\hline \multicolumn{1}{c}{ Materials } & $\begin{array}{c}\text { Density } \\
\left(\mathrm{kg} / \mathrm{m}^{3}\right)\end{array}$ & $\begin{array}{c}\text { Ultimate Tensile } \\
\text { Strength(MPa) }\end{array}$ & $\begin{array}{c}\text { Yield Strength } \\
(\mathrm{MPa})\end{array}$ & $\begin{array}{c}\text { Young's Modulus } \\
{[15]}\end{array}$ \\
\hline $\begin{array}{l}\text { Stainless Steel } \\
(304)\end{array}$ & 8000 & 505 & 215 & 193 \\
$\begin{array}{l}\text { Aluminum } \\
\text { (AA-6063) }\end{array}$ & 2700 & 89.6 & 48.3 & 68.9 \\
\hline
\end{tabular}

\section{Welding Configurations}

Three configurations are used to test the behavior of metal after welding: plate, the normal configuration; the T-configuration, in which a web is welded to the middle of a plate; and the L-configuration, in which a web is welded to the edge of a plate. Figure 1 shows the orthogonal view of different geometry configurations. In the plate configuration, the dimensions of the plate are $200 \mathrm{~mm} \times 50 \mathrm{~mm} \times 1.8 \mathrm{~mm}$ (Figure 1(a)). There are 11 tracking points to evaluate the behavior of the welding. The purple and blue is the plate used for welding. The green is the base to which the plate is fixed at a position. The clamp is used to prevent the plate dislocating when welding is in process. The tracking point at the edge tracks the distortion of the specimen and the tracking point at the weld line detects the behavior of the metal after laser welding. The tracking points are equally distributed along the weld line. In the T-configuration, four clamps are used to clamp the plate and two special clamp tools are used to clamp the web, to fix the position of the web and the plate (Figure 1(b)). The dimensions of the plate used in this configuration are $200 \mathrm{~mm} \times 50 \mathrm{~mm} \times 1.5 \mathrm{~mm}$ and the web dimension is $200 \mathrm{~mm} \times$ $1.5 \mathrm{~mm} \times 22.5 \mathrm{~mm}$. The L-configuration tests the laser weld behavior with the web welded at the edge of the plate. Figure 1(c) shows the geometry setting for the Lconfiguration. This configuration uses fewer clamps than the other two since fewer parts need to be fixed. Two clamps are used to fix the plate position and two to fix the web position. The dimensions of the plate used in this configuration are $150 \mathrm{~mm} \times 50 \mathrm{~mm} \times$ $1.5 \mathrm{~mm}$ and the web dimensions are $150 \mathrm{~mm} \times 1.5 \mathrm{~mm} \times 22.5 \mathrm{~mm}$.

\section{Finite Element Modeling}

The finite element modeling of TWBs utilizes commercial finite element software. The geometrical boundary conditions are chosen between bearings and fixations with initial forces and stiffness. Like the welders, these boundary conditions are time dependent. For the three configurations, the nodes and elements of each are different. Figure 2 shows the finite element method (FEM) of the three configurations. The time steps are critical in finite element analysis. They affect the smoothness and the accuracy of the results. The total analysis time is divided into many individual time steps (transient analysis). Each of these steps is considered small enough to allow fine discretization in order to record all the chronological and geometrical modifications during the process. Temperature is added to eight integration points of a cuboid by the movement of a heat source. When the time steps are reduced in size, the positions of the integration points may be more detailed and the results can be smoother. To achieve smoother results, smaller time steps were used. 


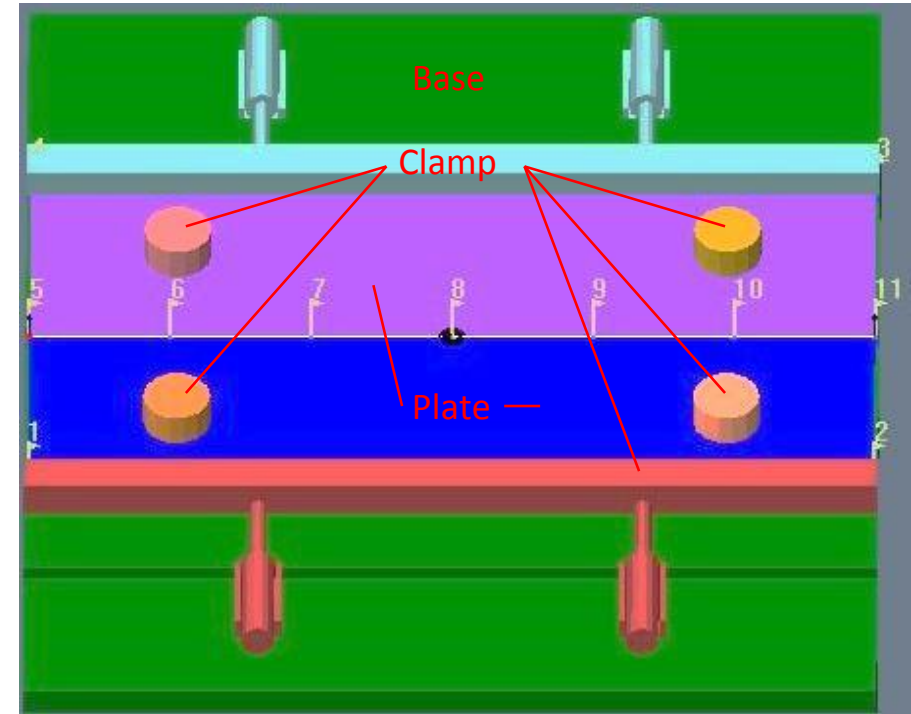

(a) Plate configuration

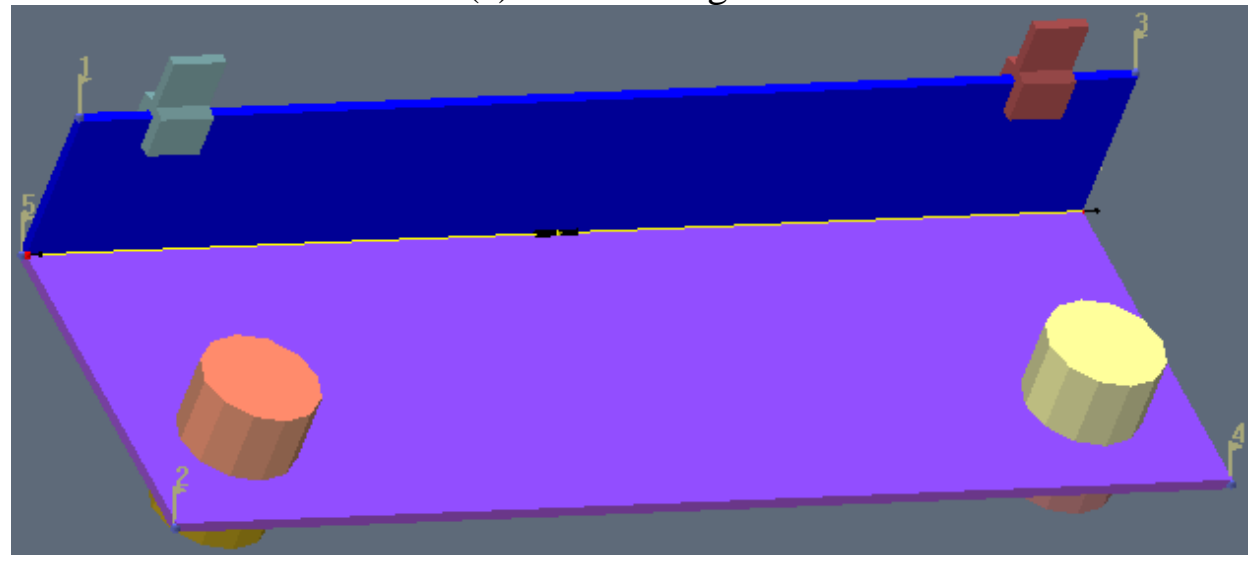

(b) L-configuration

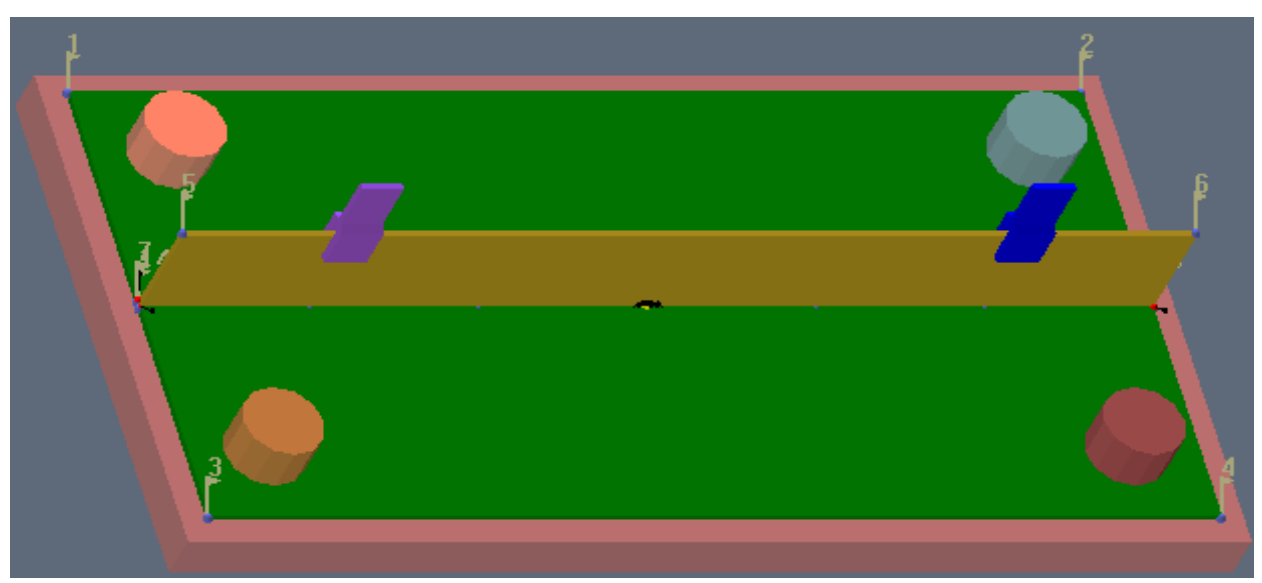

(c) T-configuration

Figure 1. Orthogonal view of different configuration geometries. 


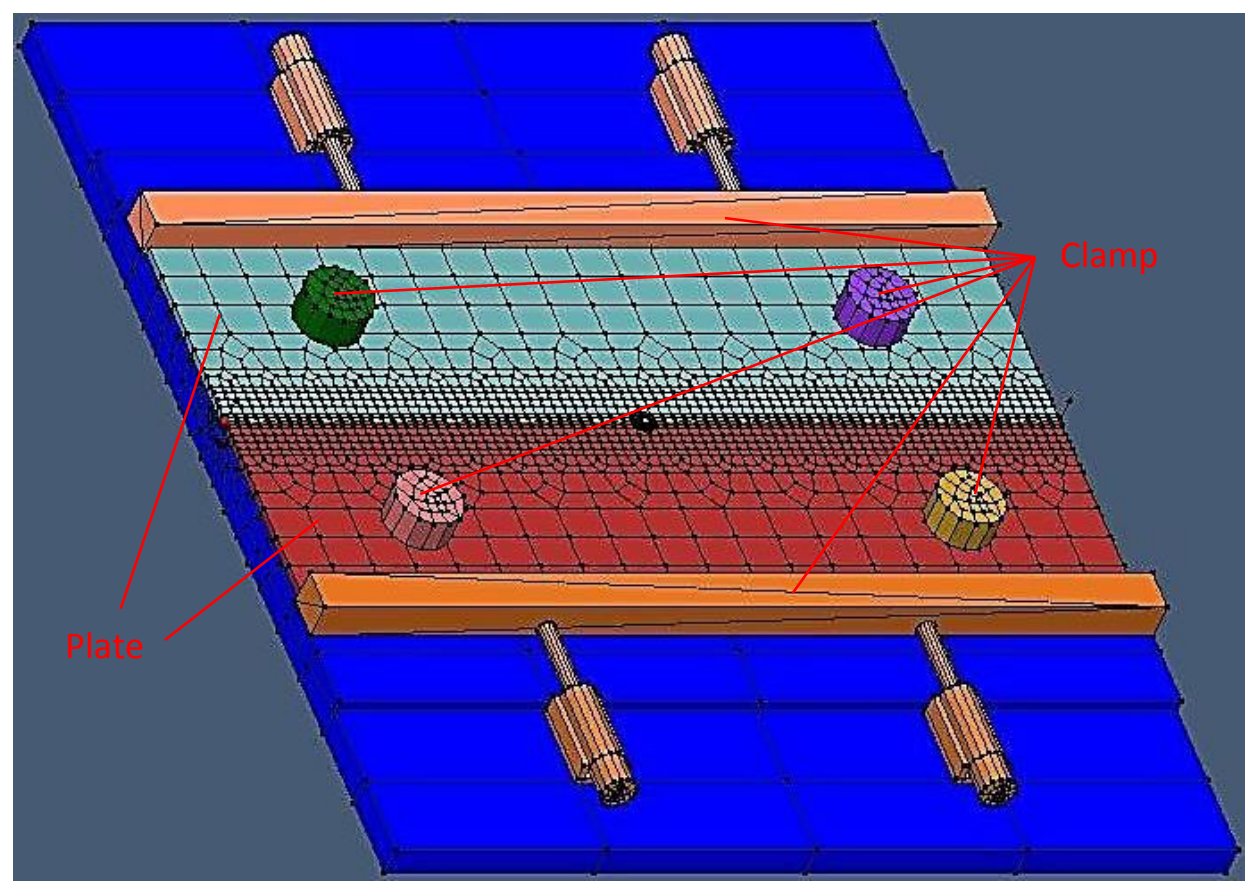

(a) Plate configuration

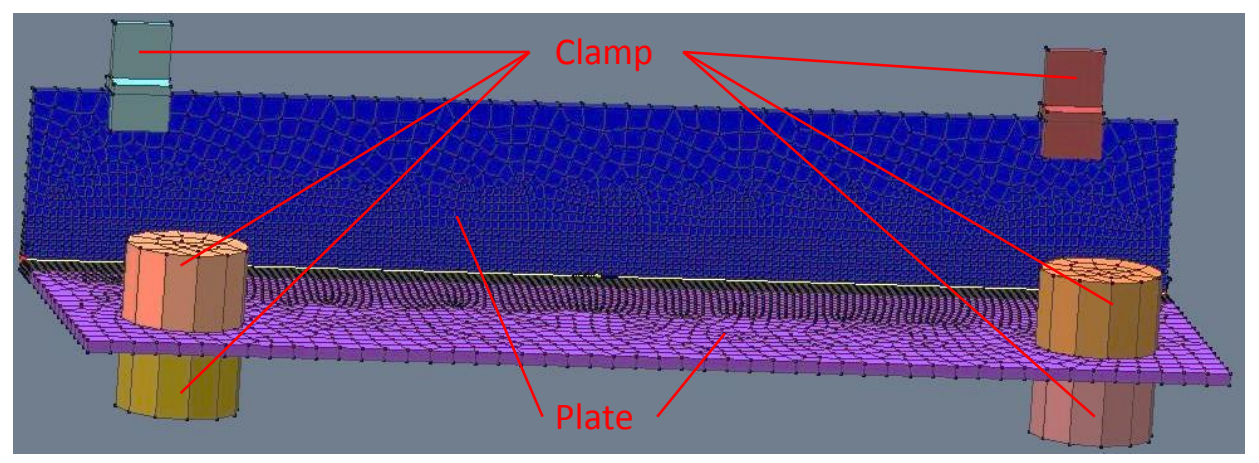

(b) L-configuration

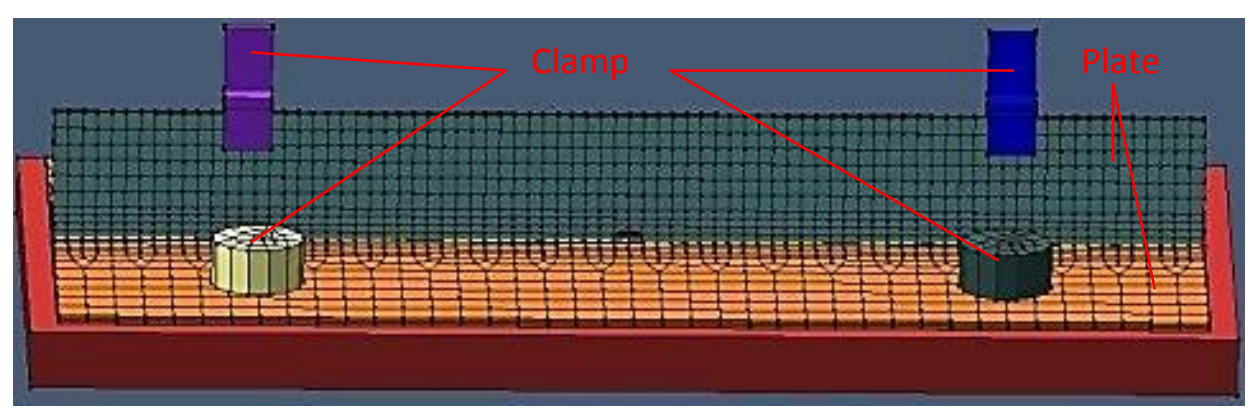

(c) T-configuration

Figure 2. Finite element modeling. 


\section{RESULTS AND DISCUSSION}

Figure 3 shows the variation of maximum principal stress (MPS) against time. Comparing all the power levels, the MPS graph trends are similar. There is no significant difference between the MPS and the changes in power. All the MPS values at the tracking point fluctuate during the welding process due to the residual stress on the plate when heating reaches that point. Comparing the $7500 \mathrm{~W}$ and the $3600 \mathrm{~W}$, the MPS values for the $3600 \mathrm{~W}$ tends to increase at a greater rate than that of the $7500 \mathrm{~W}$, due to the cooling process of the $3600 \mathrm{~W}$ being faster than that of the $7500 \mathrm{~W}$, since the heat of the $3600 \mathrm{~W}$ is lower than that of the $7500 \mathrm{~W}$. From the graphs, the MPS increment tends to be constant up to 50 seconds. The specimen temperature at that particular time is below $500 \mathrm{~K}$. The residual stress of the plate is relieved at this point.

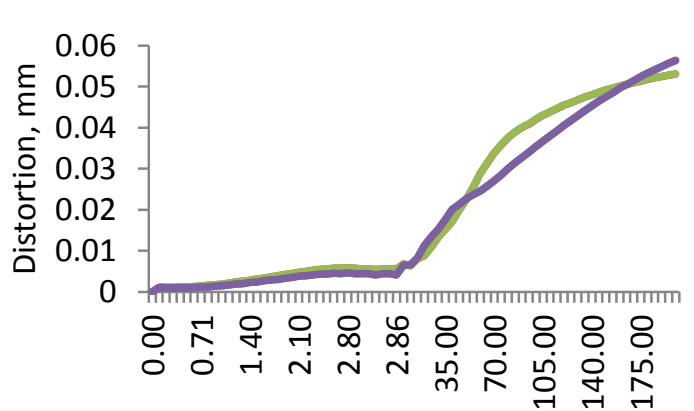

Time, $\mathrm{s}$

(a) $4500 \mathrm{~W}$

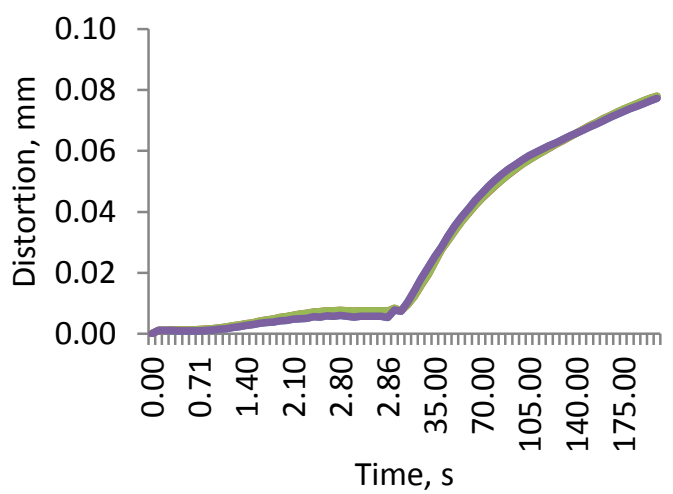

(c) $7500 \mathrm{~W}$

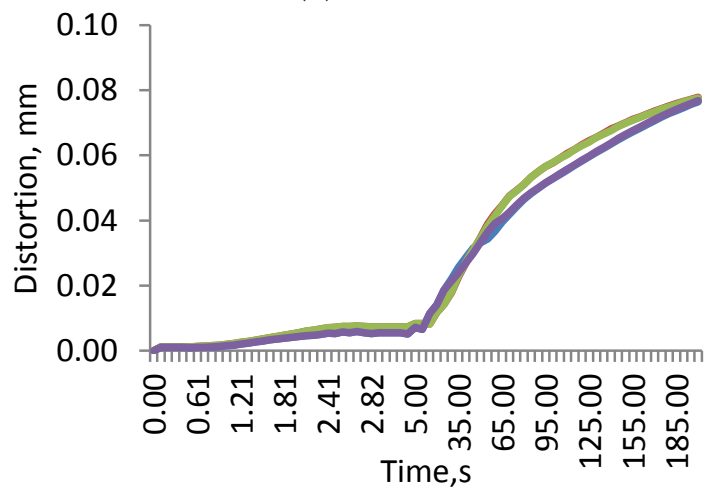

(e) $7200 \mathrm{~W}$

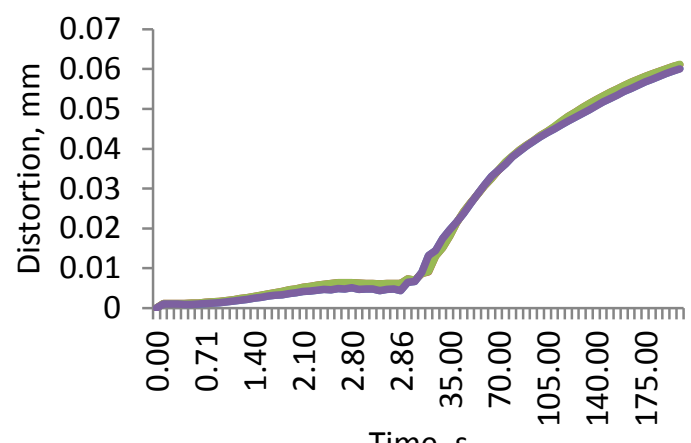

(b) $5400 \mathrm{~W}$

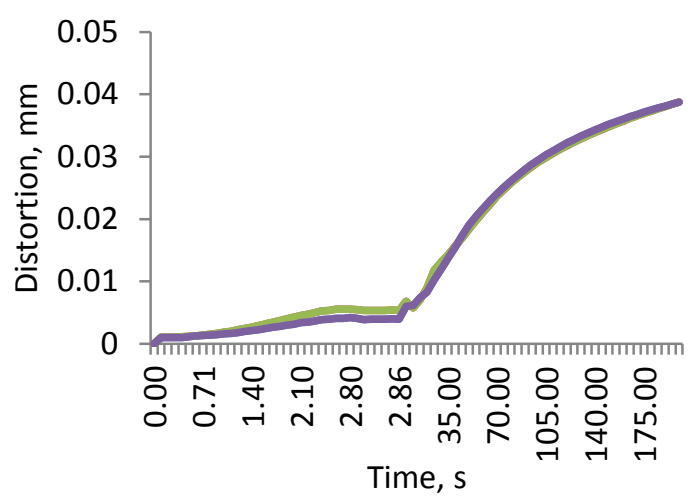

(d) $3600 \mathrm{~W}$

Figure 3. Variation in distortion against time for different power levels. 
Figure 4 shows the variation of effective plastic strain (EPS) against time. There is no significant difference in the EPS with different power levels except for the start edge of the $3600 \mathrm{~W}$ and the $4500 \mathrm{~W}$. This may due to the two plates not being fully joined due to the lower welding power used. As the joining area decreases due to not being fully joined, the strain on that point could increase since the stress applied to that point is not affected. This is due to the strain being affected by the deformation but the stress in this condition is affected by the heat supplied. As the start edge of the plate cools, the plate contracts at a similar rate to the other power levels but the area of joining is smaller than that of the others.

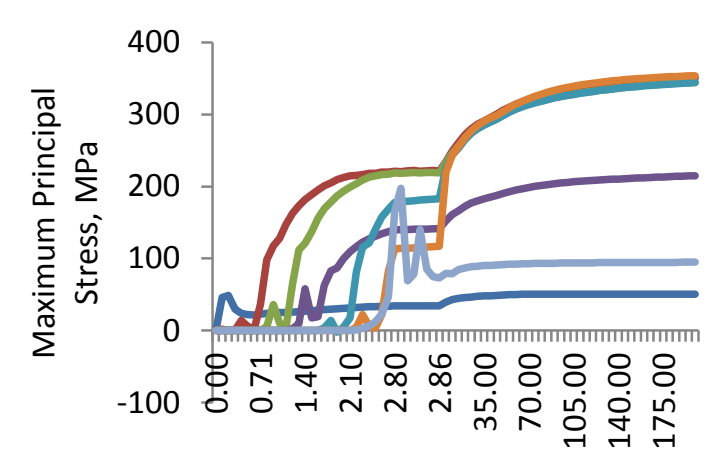

(a) $4500 \mathrm{~W}$

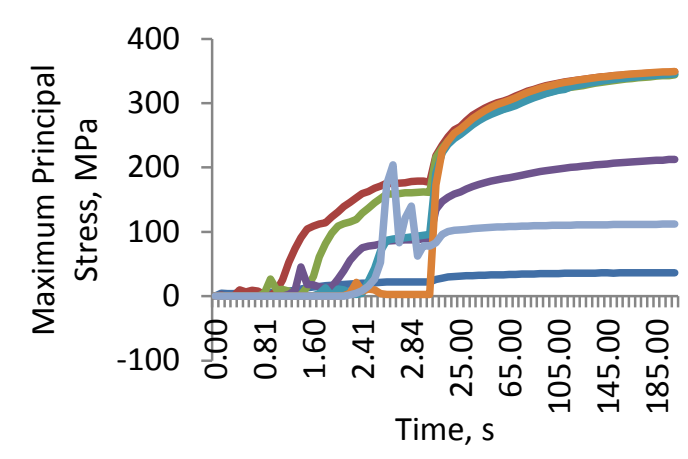

(c) $7500 \mathrm{~W}$

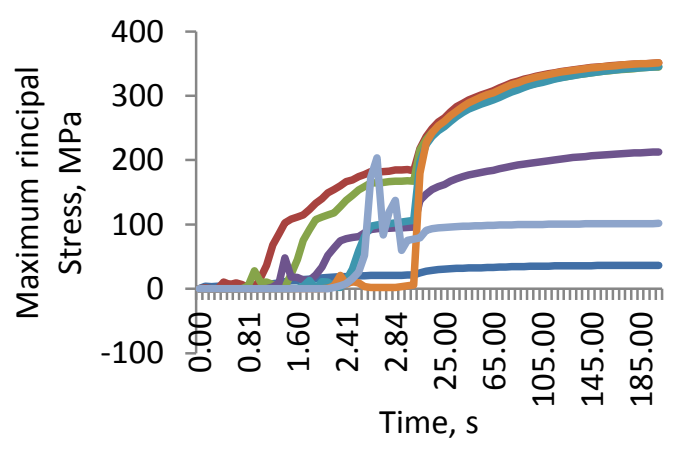

(e) $7200 \mathrm{~W}$

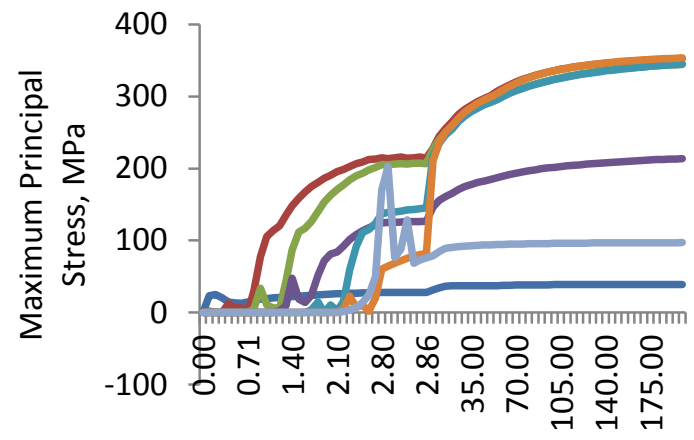

Time, s

(b) $5400 \mathrm{~W}$

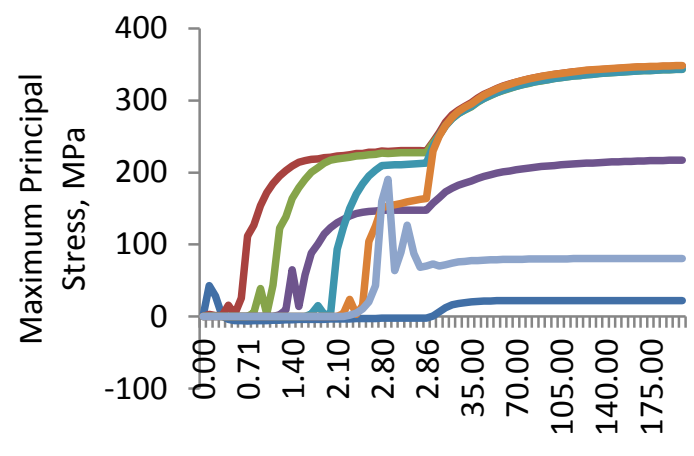

Time, s

(d) $3600 \mathrm{~W}$

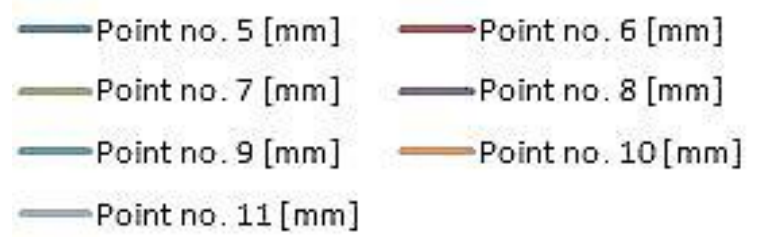

Figure 4. Variation of maximum principal stress against time for different power levels. 
Figure 5 shows the variation of effective stress (ES) against time. The graph shows that the ES value of each point fluctuates suddenly at the time the laser approaches that point. This is due to the point on the plate being subjected to stress when fusion is in process. During the fusion process, the material expands at an excessive rate and this puts stress on the plate. The sudden drop in ES is due to the drop in temperature at that point. The ES increase is again due to the shrinking of the metal at the welding area [16]. The shrinking of the metal makes the stress increase gradually. The ES value tends to be constant after the welding process due to the lower shrinkage rate and the effect on the ES is decreased. When the metal shrinkage drops to a certain level where all the stress is almost relieved, the ES tends to be constant. This is due to the cooling process and the temperature of the plate reaches a certain level where the metal solidifies making the shrinkage rate decrease.

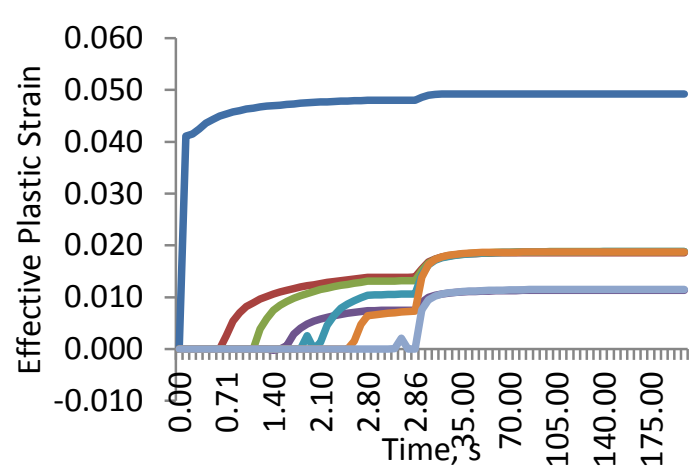

(a) $4500 \mathrm{~W}$

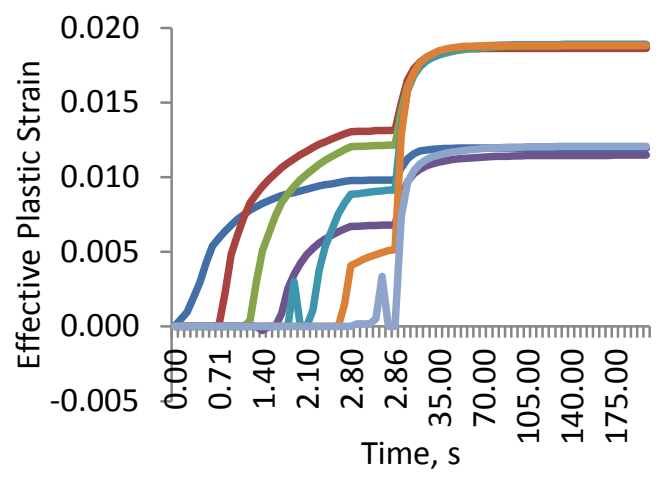

(b) $5400 \mathrm{~W}$

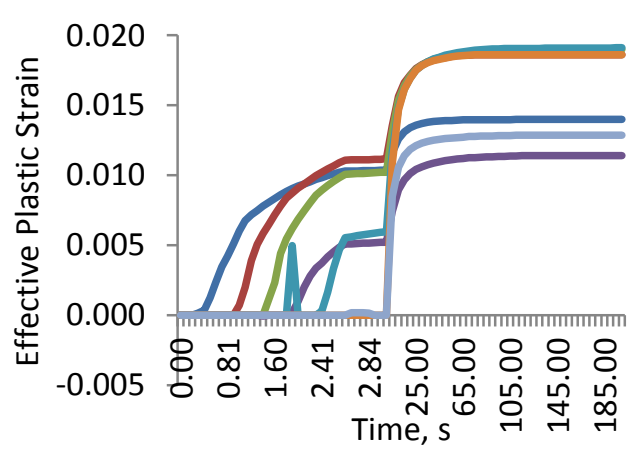

(c) $7500 \mathrm{~W}$

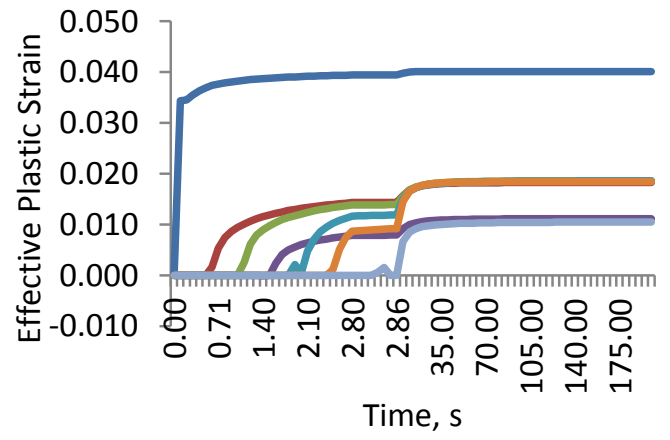

(d) $3600 \mathrm{~W}$

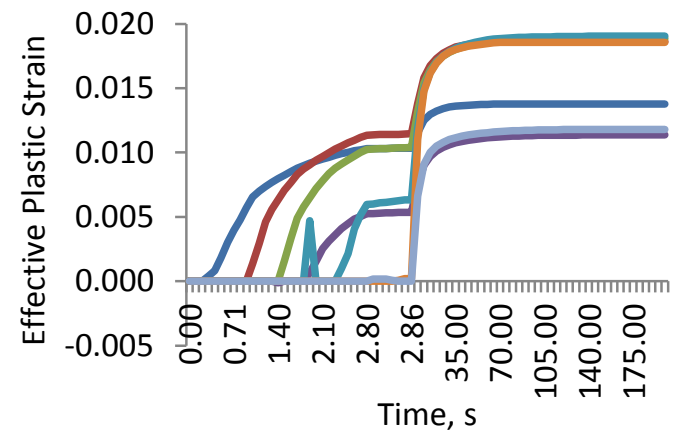

(e) $7200 \mathrm{~W}$

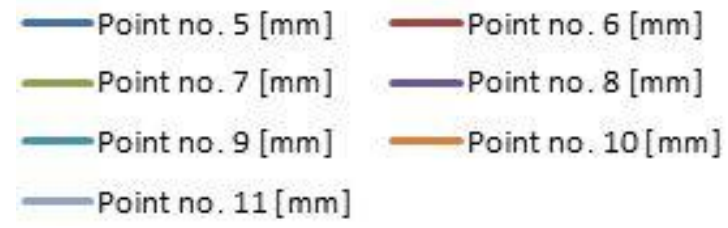

Figure 5. Variation of effective plastic strain against time for different power levels. 
Figure 6 shows the variation of MPS against time for different materials along the welding axis. Similar trends in the result can be seen during the welding process. For the steel-aluminum combination, the MPS value is lower. This may cause the aluminum to dissipate the heat faster than the steel and this reduces part of the stress, the residual stress, due to the heat during the cooling process. The steel-aluminum combination shows that the end edge has negative MPS values; this means that the stress is in the opposite direction. This may be due to the high distortion caused by deformation on the steel plate pulling the weld axis.

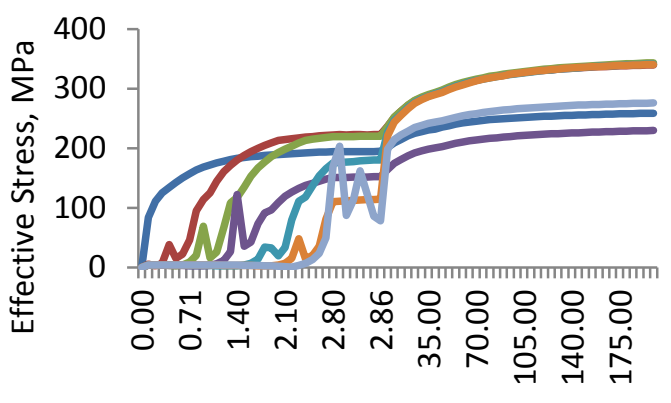

Time, s

(a) $4500 \mathrm{~W}$

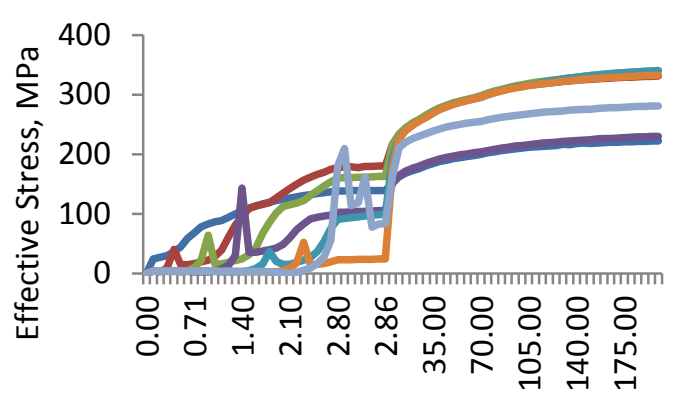

Time, s

(c) $7500 \mathrm{~W}$

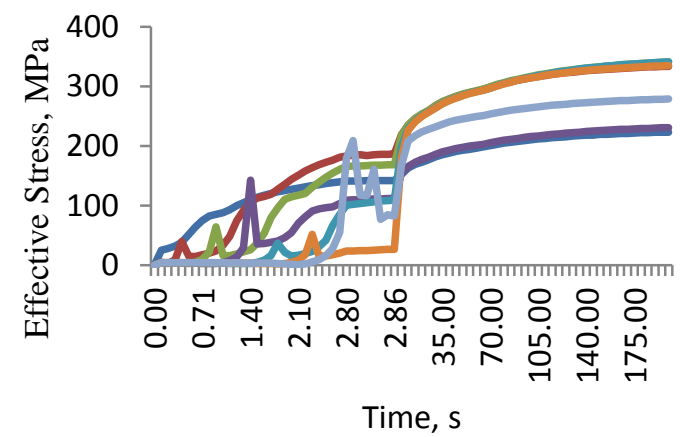

(e) $7200 \mathrm{~W}$

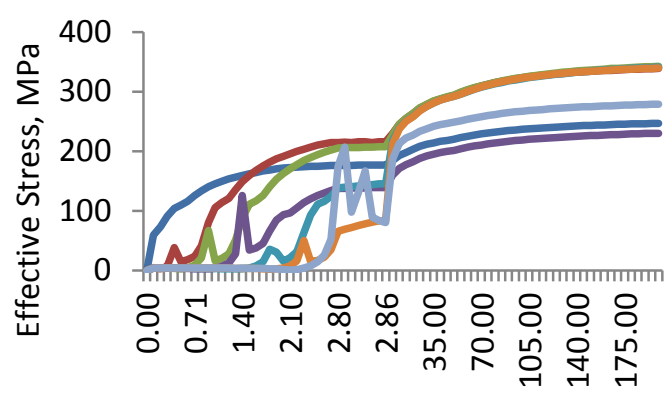

Time, $\mathrm{s}$

(b) $5400 \mathrm{~W}$

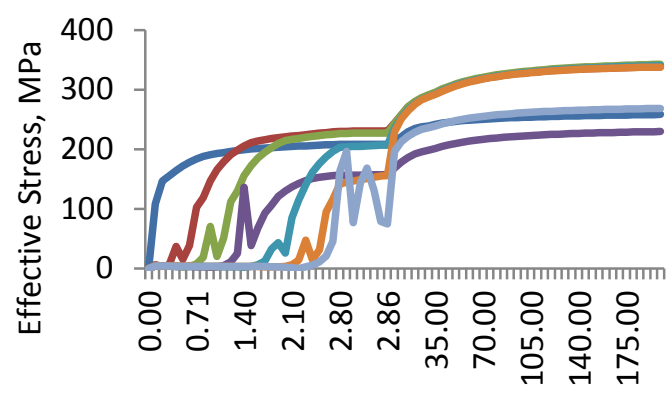

Time, $s$

(d) $3600 \mathrm{~W}$

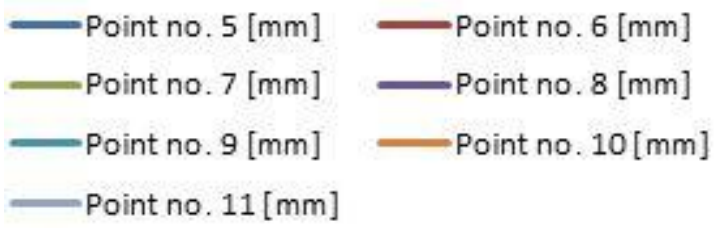

Figure 6. Variation of effective stress against time for different power. 


\section{Effects of Different Materials}

Figure 7 shows distortion against time for the different materials. The steel plate edge does not distort during the welding process, while for the aluminum plate the end of the edge is more distorted than the start of edge. It is observed that the aluminum plate is more distorted at the start and returns to a position nearer to the original before welding after the cooling process. This may be due to the stress concentration not being on the aluminum plate. The stress acting on the aluminum plate does not exceed the yield strength of the aluminum alloy so much. Thus, the aluminum did not undergo so much plastic deformation and the distortion reduced in the cooling process. As for the steel plate, the dissymmetrical distortion may be due to the heat dissipation of the steel plate not being uniform. This can result in the expansion and contraction of the steel plate not being uniform, thus affecting the distortion of the steel plate.

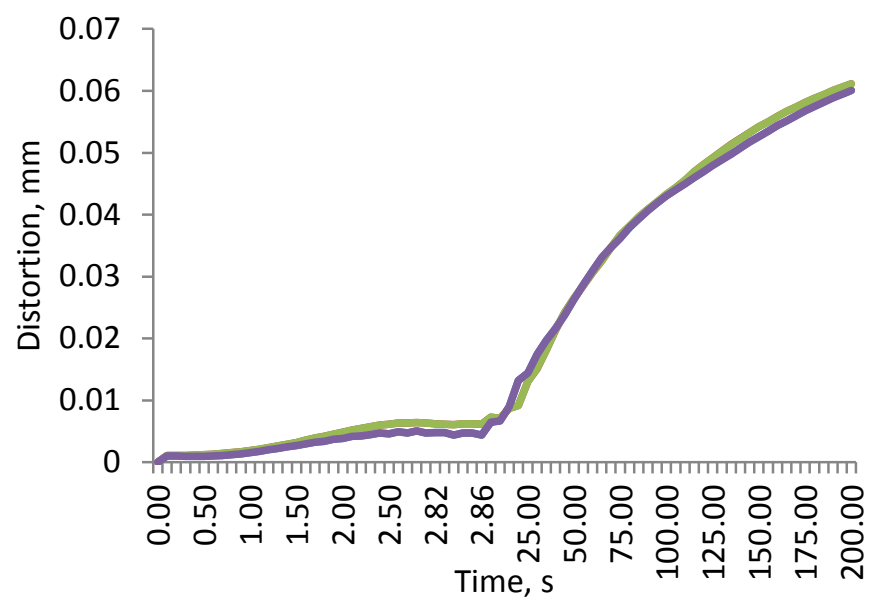

(a) Steel-steel combination

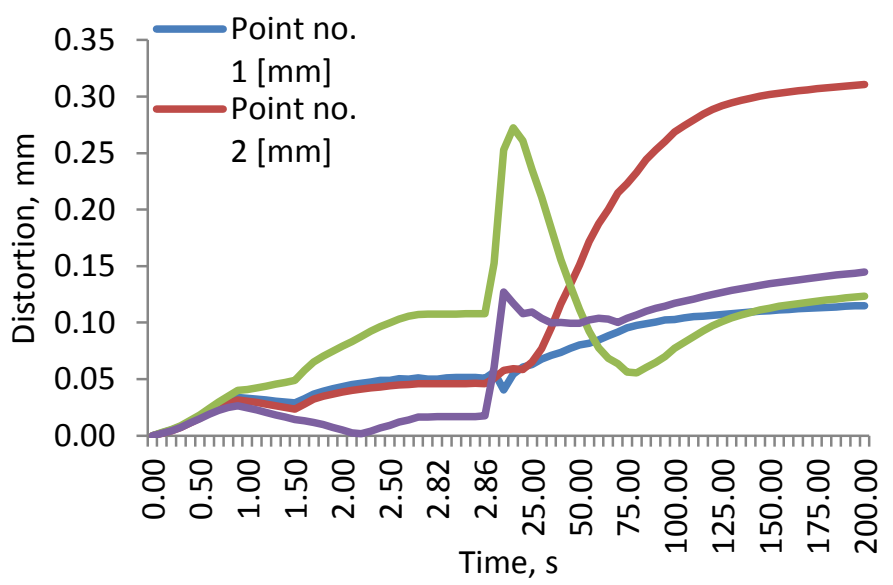

(b) Steel-aluminum combination

Figure 7. Variation of distortion against time for different materials. 
Figure 8 shows the variation of MPS against time for different materials along the weld axis. Similar trends can be seen during the welding process. For the steelaluminum combination, the MPS value is lower. This may cause the aluminum to dissipate the heat faster than steel and this reduces the residual stress due to the heat during the cooling process. The steel-aluminum combination shows that the end edge has negative MPS values, which means that the stress is in the opposite direction. This may be due to the high distortion caused by the deformation of the steel plate pulling the weld axis.

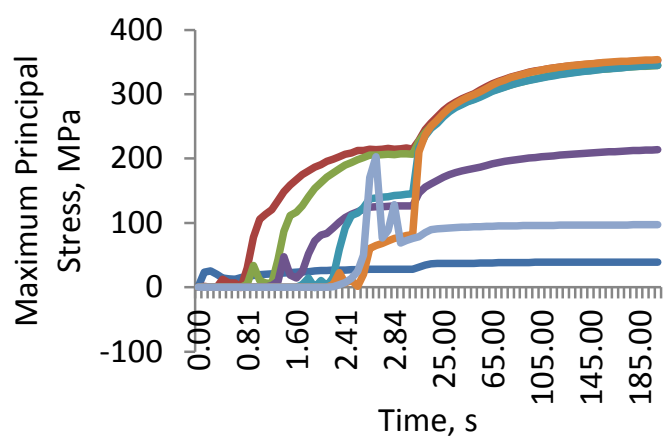

(a) Steel-steel combination

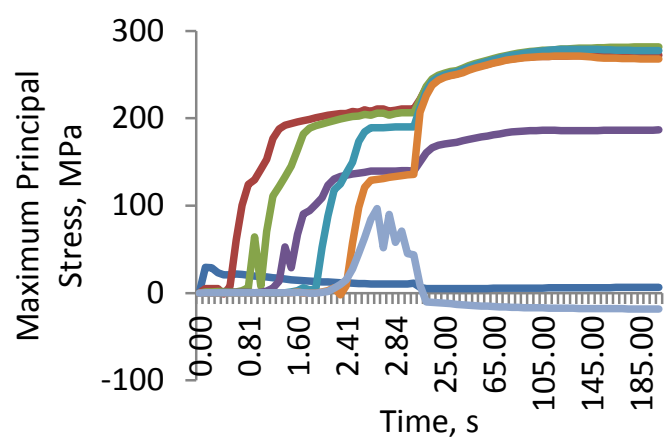

(b) Steel-aluminum combination

Figure 8. Variation of MPS against time for different materials.

Figure 9 shows the variation of EPS against time for different materials. The trend for the steel-steel and the steel-aluminum combinations is similar. The start edge and the end edge of the steel-aluminum combination shows a lower EPS which means that the strain on that point is low. This may be due to the gap between the plates which means that the joint at the start edge does not actually exist. For the end edge, the plastic strain jumps to a very high value then returns to zero when welding. During the cooling process, the EPS tends to a constant at low value. This may be due to the point reaching fatigue strain.

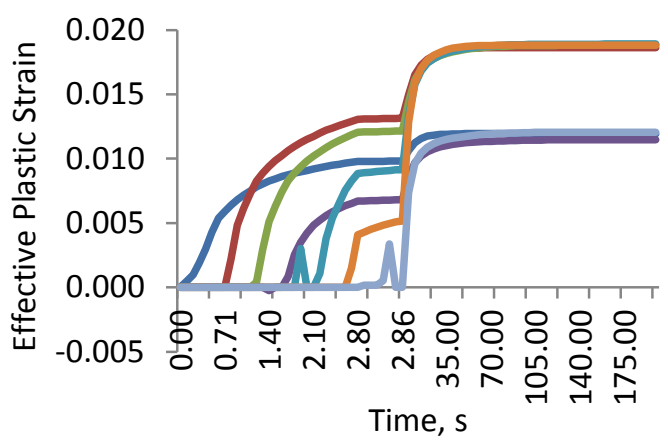

(a) Steel-steel combination

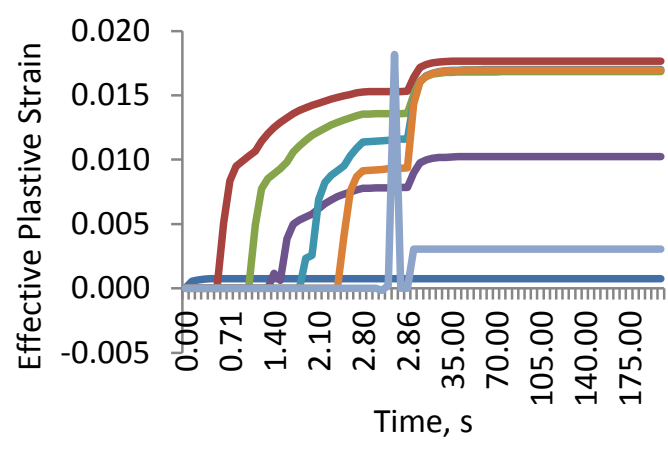

(b) Steel-aluminum combination

Figure 9. Variation of effective plastic strain against time for different materials. 


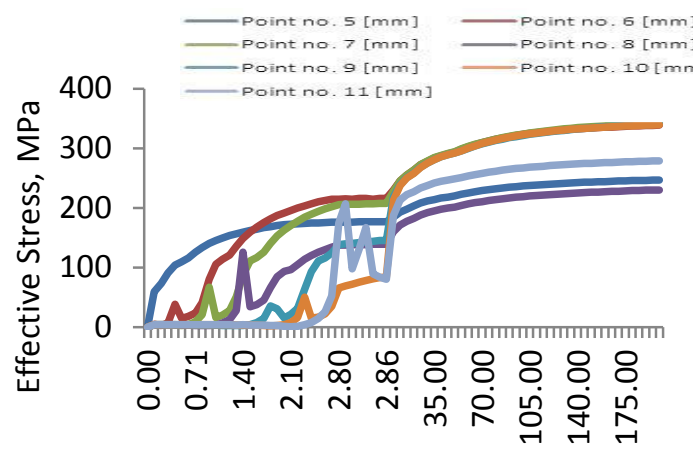

Time, s

(a) Steel-steel combination

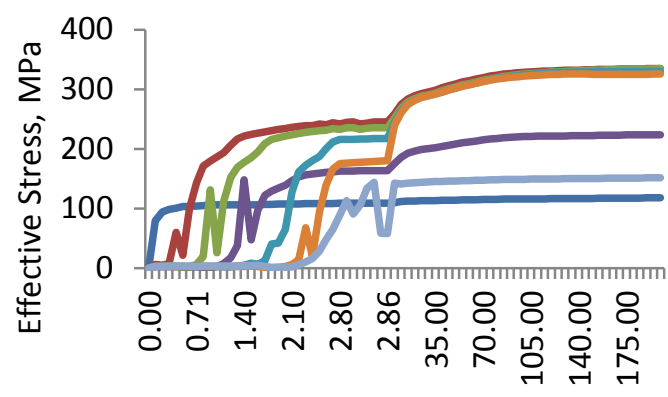

Time, $s$

(b) Steel-aluminum combination

Figure 10. Variation of ESs against time for different materials

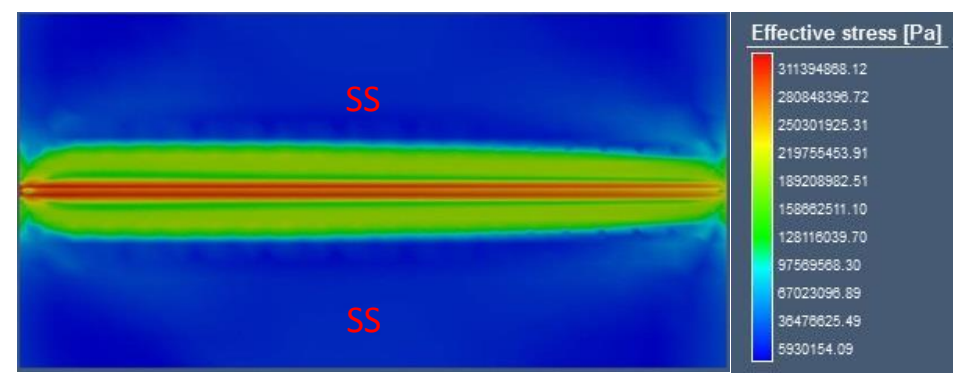

(a) After welding

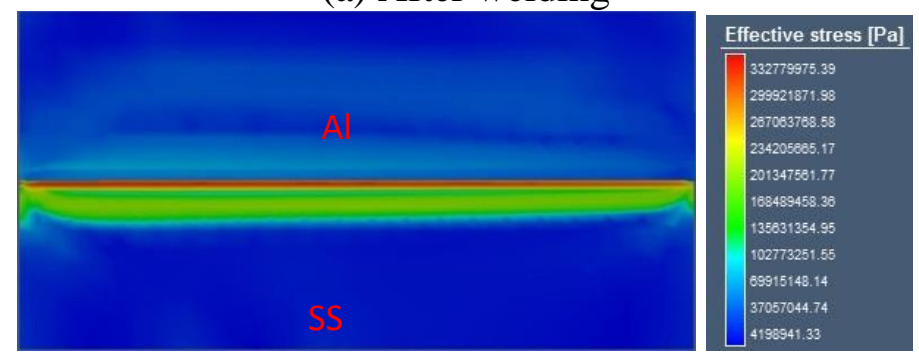

(b) After welding

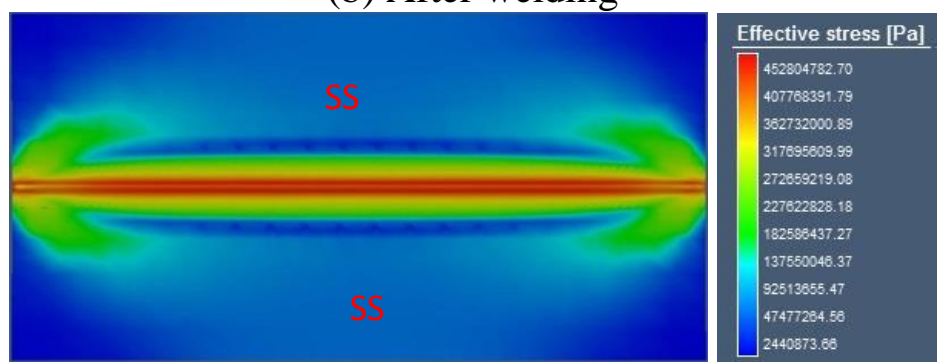

(c) After cooling
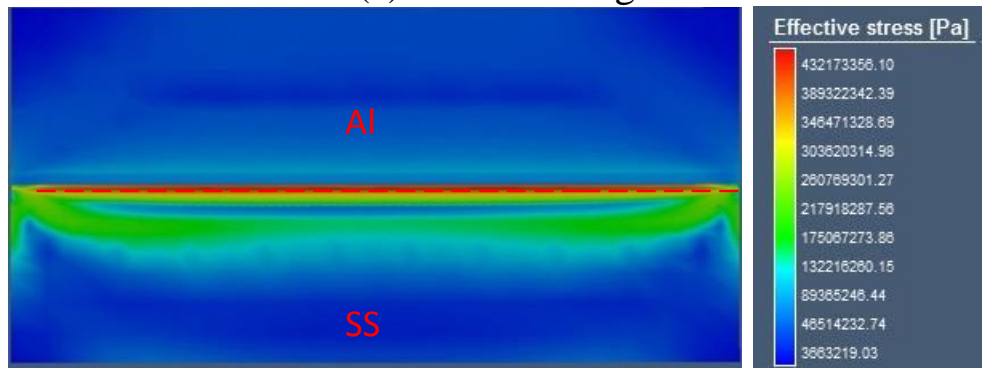

(d) After cooling

Figure 11. Contours of effective stress. 
Figure 10 shows the variation of ES against time for different materials. Similar trends appear where the ESs of all the points fluctuate during the welding process, except at point 5 which tends to a constant from the start after the first increment. The ES of the steel-steel combination is more precise compared to the steel-aluminum combination. The distribution of the ES is clearer in Figure 11 which shows the contours of the ES. From the contours, it is clearly shown that the stress is actually concentrated on the steel plate in the steel-aluminum combination. This is due to the heat of the aluminum plate being dissipated faster than that of the SS.

\section{CONCLUSIONS}

Stress analysis using the finite element method was undertaken. The critical location of the TWB at the start edge and end edge of the plate is determined. High power is required to fuse the metal; however, higher power leads to a greater heat-affected zone. Dissimilar metals and configurations affect the weld behavior where weld power needs to be used to achieve better welding effects. Finite element analysis is a prediction method that can be used before producing a product or before conducting experiments. The heat affected zone increases during the welding process when the power increases. Increasing the power also increases the distortion of the TWB. Using different TWB materials is widespread in automotive applications. The common materials used are aluminum and steel. The welding process for these two materials is not easy where their mechanical and thermal properties are not identical. The heat affected zone during the welding process is not identical and the power used has to be adjusted for good laser welding. TWB distortion is another problem caused by this combination. The method used in welding SS could not be used for combinations of different materials.

\section{ACKNOWLEDGEMENTS}

The authors would like to thanks to Unviersiti Malaysia Pahang for financial and laboratories facilities under university research grant (Project No. RDU120310).

\section{REFERENCES}

[1] Kinsey B, Liu Z, Cao J. A novel forming technology for tailor-welded blanks. Journal of Materials Processing Technology. 2000;99:145-53.

[2] Shah LH, Akhtar Z, Ishak M. Investigation of aluminum-stainless steel dissimilar weld quality using different filler metals. International Journal of Automotive and Mechanical Engineering. 2013;8:1121-31.

[3] Rahman MM, Arrifin AK, Nor MJM, Abdullah S. Fatigue analysis of spotwelded joint for automative structures. Structural Durability and Health Monitoring. 2008;4:173-80.

[4] Rahman MM, Bakar RA, Noor MM, Rejab MRM, Sani MSM. Fatigue life prediction of spot-welded structures: A finite element analysis approach. European Journal of Scientific Research. 2008;22:444-56.

[5] Rahman MM, Rosli AB, Noor MM, Sani MSM, Julie JM. Effects of spot diameter and sheets thickness on fatigue life of spot welded structure based on FEA approach. American Journal of Applied Sciences. 2009;6:137-42.

[6] Zhao K, Chun B, Lee J. Finite element analysis of tailor-welded blanks. Finite Elements in Analysis and Design. 2001;37:117-30. 
[7] Charde N. Microstructure and fatigue properties of dissimilar spot welds joints of AISI 304 and AISI 1008. International Journal of Automotive and Mechanical Engineering. 2013;7:882-99.

[8] Hatifi MM, Firdaus MH, Razlan AY. Modal analysis of dissimilar plate metal joining with different thicknesses using MIG welding. International Journal of Automotive and Mechanical Engineering. 2014;9:1723-33.

[9] Ishak M, Shah LH, Aisha ISR, Hafizi W, Islam MR. Study of resistance spot welding between aisi 301 stainless steel and AISI 1020 carbon steel dissimilar alloys. Journal of Mechanical Engineering and Sciences. 2014;6:793-806.

[10] Nuraini AA, Zainal AS, Azmah Hanim MA. The effects of welding parameters on butt joints using robotic gas metal arc welding. Journal of Mechanical Engineering and Sciences. 2014;6:988-94.

[11] Anand D, Chen D, Bhole S, Andreychuk P, Boudreau G. Fatigue behavior of tailor (laser)-welded blanks for automotive applications. Materials Science and Engineering: A. 2006;420:199-207.

[12] Davies R, Grant G, Khaleel M, Smith M, Oliver HE. Forming-limit diagrams of aluminum tailor-welded blank weld material. Metallurgical and Materials Transactions A. 2001;32:275-83.

[13] Luo Y. Adaptive nearest-nodes finite element method guided by gradient of linear strain energy density. Finite Elements in Analysis and Design. 2009;45:925-33.

[14] Raymond SD, Wild PM, Bayley CJ. On modeling of the weld line in finite element analyses of tailor-welded blank forming operations. Journal of Materials Processing Technology. 2004;147:28-37.

[15] Eitssayeam S, Intatha U, Rujijanagul G, Pengpat K, Tunkasiri T. Structural and electrical properties characterization of $(1-\mathrm{x}) \mathrm{PbZr} 0.52 \mathrm{Ti} 0.48 \mathrm{O}_{3}-\mathrm{xBaFe} 0$. 5Nb0. $5 \mathrm{O} 3$ system. Applied Physics A. 2006;83:295-9.

[16] Radaj D. Heat effects of welding: temperature field, residual stress, distortion: Springer Verlag; 1992. 